\title{
Modulation of Locomotor Activation by the Rostromedial Tegmental Nucleus
}

\author{
Heather N Lavezzi', Kenneth P Parsley' and Daniel S Zahm*,' \\ 'Department of Pharmacological and Physiological Science, Saint Louis University School of Medicine, St Louis, MO, USA
}

\begin{abstract}
The rostromedial tegmental nucleus (RMTg) is a strong inhibitor of dopamine neurons in the ventral tegmental area (VTA) reported to influence neurobiological and behavioral responses to reward omission, aversive and fear-eliciting stimuli, and certain drugs of abuse. Insofar as previous studies implicate ventral mesencephalic dopamine neurons as an essential component of locomotor activation, we hypothesized that the RMTg also should modulate locomotion activation. We observed that bilateral infusions into the RMTg of the gamma-aminobutyric acid $A\left(G_{A B A}\right)$ agonist, muscimol, indeed activate locomotion. Alternatively, bilateral RMTg infusions of the $\mathrm{GABA}_{A}$ receptor antagonist, bicuculline, suppress robust activations of locomotion elicited in two distinct ways: (I) by disinhibitory stimulation of neurons in the lateral preoptic area and (2) by return of rats to an environment previously paired with amphetamine administration. The possibility that suppressive locomotor effects of RMTg bicuculline infusions were due to unintended spread of drug to the nearby VTA was falsified by a control experiment showing that bilateral infusions of bicuculline into the VTA produce activation rather than suppression of locomotion. These results objectively implicate the RMTg in the regulation of locomotor activation. The effect is important because much evidence reported in the literature suggests that locomotor activation can be an involuntary behavioral expression of expectation and/or want without which the willingness to execute adaptive behaviors is impaired. Neuropsychopharmacology (20I5) 40, 676-687; doi:I0.1038/npp.20 I4.223; published online 24 September 20I4
\end{abstract}

\section{INTRODUCTION}

Locomotor activation, sometimes called 'exploratory' locomotion and alternatively referred to as SEEKING behavior (Ikemoto and Panksepp, 1999), is a state of augmented ambulation that frequently occurs in the absence of a clear goal object, as, eg, after psychostimulant drug administration or electrical self-stimulation of certain brain sites (Roberts and Carey, 1965; Kelly et al, 1975), but it may also be goal-related, as manifested in the enhanced (conditioned) locomotion of rodents returned to an environment previously paired with psychostimulant drug administration (Post et al, 1981; Beninger and Hahn, 1983; Beninger and Herz, 1986; Gold et al, 1988; Hotsenpiller et al, 2001). Much evidence supports the inference that locomotor activation is accompanied by an anticipatory affective component (see, eg, Roberts and Carey, 1965; Mary Christopher and Butter, 1968), which has been likened to a psychological state of 'wanting' (Berridge and Robinson 1998; Berridge 2012). Release of dopamine into the accumbens (Acb) from the axon terminations of ventral tegmental area (VTA) neurons is thought to be a physiological substrate of both locomotor activation and this

*Correspondence: Dr DS Zahm, Department of Pharmacological and Physiological, Science, St Louis University School of Medicine, I 402 S., Grand Boulevard, St Louis, MO 63104, USA, Tel: + I 3149778003 , Fax: + 314977 64 I I, E-mail: zahmds@slu.edu

Received 10 April 2014; revised 15 August 2014; accepted 18 August 2014; accepted article preview online 28 August 2014 presumptive affective state (Kelly et al, 1975; Kalivas et al, 1983; Kalivas and Duffy 1990; Steinberg et al, 1994) and both are subject to neuroadaptive changes (Kalivas and Stewart, 1991; Grimm et al, 2001; Berridge 2012), leading to further augmentation not only of locomotion but also the subjective anticipatory component, in the form of craving, such as is experienced following repeated exposure to drugs of abuse (Robinson and Berridge 1993; Grimm et al, 2001). Other support for an affective motivational component of VTA-Acb DA release is attached to the observations that (1) pharmacological enhancement of DA release in the Acb potentiates responding for second-order reinforcement (Taylor and Robbins, 1984; 1986; Cador et al, 1991) and (2) willingness to exert goal-directed effort is impaired by blockade of VTA-Acb DA transmission (Salamone et al, 2003; Salamone and Correa, 2012).

The rostromedial tegmental nucleus (RMTg), a recently discovered structure located in the mesopontine tegmentum (Jhou, 2005; Jhou et al, 2009a, b; Kaufling et al, 2009), projects preferentially and strongly to (Jhou et al, 2009a, b, Balcita-Pedicino et al, 2011; Bourdy et al, 2014) and thus is a strong inhibitor of (Hong et al, 2011; Lecca et al, 2011, 2012; Matsui and Williams, 2011; Matsui et al, 2014) dopamine neurons in the VTA and substantia nigra compacta $(\mathrm{SNc})$. RMTg is implicated together with the VTA in behavioral responding to reward omission, aversive stimuli, feareliciting stimuli, and certain drugs of abuse (Jhou et al, 2009a, 2013; Hong et al, 2011; Lecca et al, 2011, 2012; Matsui and Williams, 2011; Wasserman et al, 2013) and, more recently, with the SNc in motor skill and motor learning 
(Bourdy et al, 2014). Insofar as activation specifically of VTA dopamine neurons and accompanying release of dopamine in the Acb is the sine qua non of locomotor activation (references cited above), we hypothesized that the RMTg should also modulate locomotion. We addressed this by testing whether RMTg activity alters basal locomotion, after which we sought to determine whether robust locomotor activations elicited by lateral preoptic area (LPO) stimulation (Mogenson and Nielsen 1983; Mogenson et al, 1985; Shreve and Uretsky 1988, 1989, 1991; Willins et al, 1992; Zahm et al, 2014) and cues linked to prior amphetamine experiences are altered by activating the RMTg.

\section{MATERIALS AND METHODS}

\section{Animals}

Male Sprague-Dawley rats (Harlan, Indianapolis, IN) weighing 225-350 g were used in accordance with guidelines mandated in the National Institutes of Health Guide for the Care and Use of Laboratory Animals. The rats were housed on a 12-h light-dark cycle in groups of two to four until surgeries were performed, after which all were singly housed. Access to food and water was provided ad libitum.

\section{Placement of Guide Cannulae}

Rats were deeply anesthetized by intraperitoneal injections of a mixture of ketamine $(72 \mathrm{mg} / \mathrm{kg})$ and xylazine $(11.2 \mathrm{mg} / \mathrm{kg})$ given as a cocktail consisting of $45 \%$ ketamine $(100 \mathrm{mg} / \mathrm{ml})$, $35 \%$ xylazine $(20 \mathrm{mg} / \mathrm{ml})$ and $20 \%$ saline at $0.16 \mathrm{ml} / 100 \mathrm{~g}$ of body weight. The anesthetized rats were placed in a Kopf stereotaxic apparatus. Incisions were made in the scalp to expose the skull into which small burr holes were drilled at positions overlying the injection sites. Separate groups of rats received cannula placements (1) bilaterally above the RMTg (AP-6.7 mm, ML $\pm 0.6, \mathrm{DV}-5.45 \mathrm{~mm}$ ), (2) bilaterally above the VTA $(\mathrm{AP}-5.4 \mathrm{~mm}, \mathrm{ML} \pm 0.6, \mathrm{DV}-6.2 \mathrm{~mm})$ and (3) both unilaterally above the LPO (AP- $-0.6 \mathrm{~mm}$, $\mathrm{ML} \pm-3.5,20^{\circ}, \mathrm{DV}-5.45 \mathrm{~mm}$ ) and bilaterally above the RMTg. Guide cannulae aimed at the LPO were implanted at an angle of $20^{\circ}$ in the mediolateral plane so as to avoid the lateral ventricle; all others were set vertically. The cannulae were inserted to a depth $2 \mathrm{~mm}$ above the center of the intended target and fixed with dental cement anchored to stainless steel screws set in the skull. Stainless steel wire obturators were inserted into the guide cannulae to maintain patency. The incisions were closed with wound clips, and each rat was given an i.p. injection of Rimadyl (carprophen, $10 \mathrm{mg} / \mathrm{kg})$ or Buprenex SR $(1 \mathrm{mg} / \mathrm{kg})$ and kept warm until it awoke.

\section{Behavior Testing}

One week after cannulae were implanted (or 3 days in some initial experiments), the rats were brought to the behavior testing room where, after at least $20 \mathrm{~min}$ of habituation, locomotion was measured in activity monitors, each comprising a square, white floor $\left(43.2 \times 43.2 \mathrm{~cm}^{2}\right)$ and $30.5 \mathrm{~cm}$ high clear plexiglass walls (Med Associates, St Albans, VT). Fixtures containing horizontal rows of 16 point-source infrared illuminators set at a height of $2.54 \mathrm{~cm}$ from the floor and aimed at equispaced detectors affixed on the opposite wall were fastened to adjacent walls of the chambers so as to form a grid of $16 \times 16$ intersecting beams for measurement of horizontal (forward) locomotion. Beam breaks, a reflection of distance traveled, were evaluated with the aid of the Activity Monitor software (Med Associates). The monitors were housed in dimly illuminated soundattenuating chambers with exhaust fans running (Med Associates).

Before the rats were put in the activity monitors, the obturators were removed and injector cannulae connected by a short length of polyethylene tubing (PE 20 0.38/1.09, Stoelting, Wood Dale, IL, cat. no. 51155) to the Luer needle of a 1.0- $\mu$ l Hamilton syringe were inserted through the guide cannulae to a depth of $2 \mathrm{~mm}$ beyond their distal tips. Infusate was propelled at a rate of $0.25 \mu \mathrm{l} / \mathrm{min}$ by a syringe pump (Harvard Apparatus, Holliston, MA, model '11' plus). LPO infusions lasted $1 \mathrm{~min}$; RMTg and VTA infusions lasted $30 \mathrm{~s}$. After testing, the obturators were replaced, and the rats were returned to their home cages.

\section{Drugs}

All drugs were dissolved in sterile $0.9 \%$ sodium chloride (Hospira, Lake Forest, IL), which was used for vehicle infusions. The $\mathrm{GABA}_{\mathrm{A}}$ receptor antagonist, 9(R)-(-)-bicuculline methbromide (Sigma Chemical, St Louis, MO), was prepared at a dilution of $1 \mathrm{mg} / 3 \mathrm{ml}$ vehicle, which resulted in the delivery of $33.5 \mathrm{ng}$ in $0.125 \mu \mathrm{l} / 30 \mathrm{~s}$ of infusion. The $\mathrm{GABA}_{\mathrm{A}}$ receptor agonist, muscimol hydrobromide (Sigma), was prepared at a dilution of $1 \mathrm{mg} / 2 \mathrm{ml}$ vehicle, which resulted in the delivery of $37 \mathrm{ng}$ in $0.125 \mu \mathrm{l} / 30 \mathrm{~s}$ of infusion. As discussed further in the Results and Discussion sections, bicuculline infusions into the LPO were done unilaterally for $60 \mathrm{~s}$, resulting in a delivery of $67 \mathrm{ng}$ in $0.25 \mu \mathrm{l}$. RMTg and VTA infusion were done for $30 \mathrm{~s}$, resulting in the delivery of the amounts aforestated. D-Amphetamine hemisulfate salt C-II (Sigma) was prepared at a dilution of $1 \mathrm{mg} / \mathrm{ml}$ vehicle and injected i.p. at a dose of $1 \mathrm{mg} / \mathrm{kg}$.

\section{Effects of Bicuculline and Muscimol Infusions into the RMTg and VTA on Basal and LPO-Stimulated Locomotion}

In rats with cannula placements targeted to the RMTg and LPO, testing began at time 0 with priming infusions into the first structure (either the LPO unilaterally or RMTg bilaterally) after which locomotor activity was recorded between 2 and $6 \mathrm{~min}$ followed by infusions into the second structure (RMTg if LPO had been first; LPO if RMTg had been first) and recording of locomotor activity from 10 to $20 \mathrm{~min}$. The rats $(n=7)$ were tested under the following conditions on separate successive days in the following order: vehicle into the RMTg followed by (1) vehicle or (2) bicuculline into the LPO; bicuculline into the RMTg followed by (3) vehicle or (4) bicuculline into the LPO; and (5) vehicle into the LPO followed by muscimol into the RMTg (Figure 1i and $j$ ). In rats with cannula placements targeted to the VTA $(n=8)$, testing began at time 0 with infusions of muscimol, bicuculline, or vehicle, on successive days, after which locomotor testing proceeded for $20 \mathrm{~min}$. 


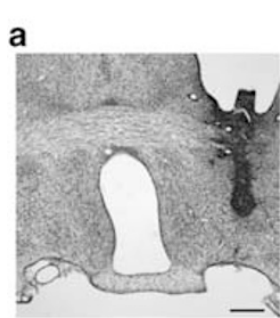

b

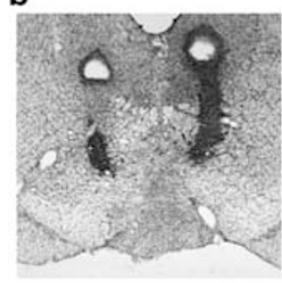

i

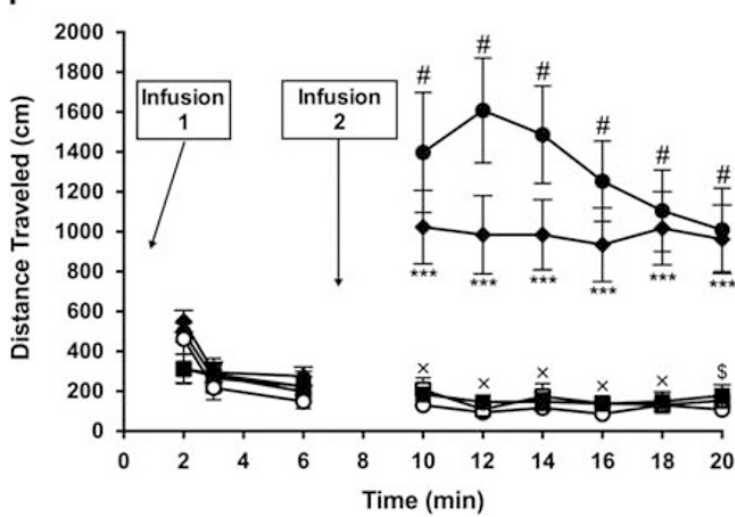

C

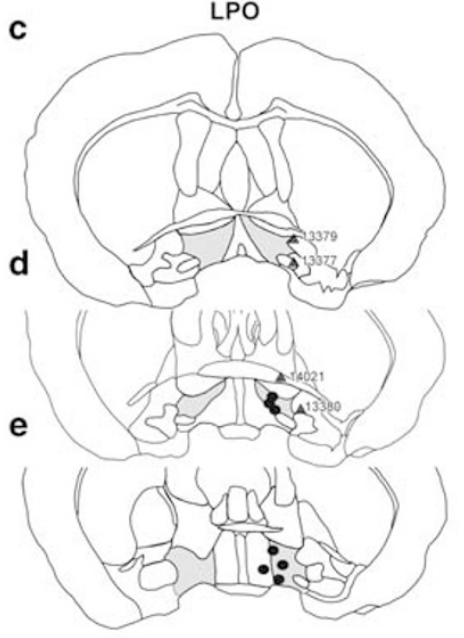

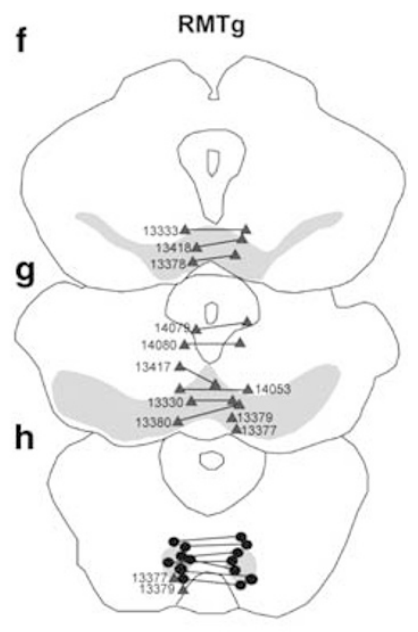

j

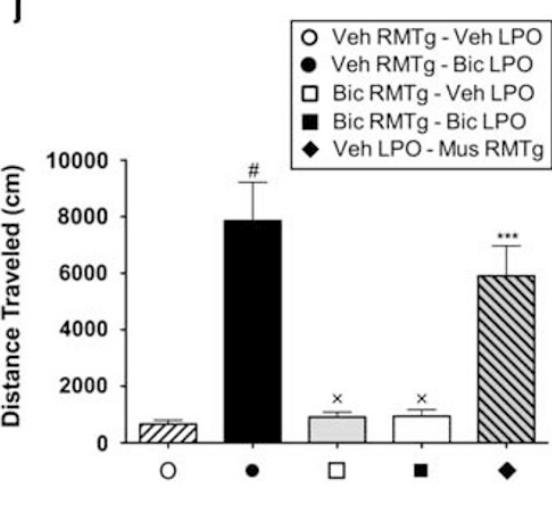

Figure I ( $a$ and b) Nissl-stained sections of the brain showing representative cannula placements for $L P O(a)$ and RMTg (b). ( $c-h$ ) Diagrams of series of sections ordered from rostral (top) to caudal (bottom) showing infusion sites. The gray shading in the sections illustrates the approximate boundaries of the LPO (c-e), VTA ( $f$ and g) and RMTg (h). Black dots indicate on-target infusion sites; gray triangles indicate off-target sites and are identified by corresponding case numbers. (i) Distance traveled following infusions of vehicle, muscimol, and bicuculline into the LPO and RMTg. For all conditions, $n=7$. Infusion I indicates the initial infusions, which are provided in the legend above panel (j). Second infusions (Infusion 2 in panel (i)) were given 6 min later. Distance traveled was recorded in 2-min bins for a total of 20 min and analyzed with a two-way ANOVA (distance $\times$ time) with Tukey's multiple comparison's test post hoc. (j) Graph showing total distances traveled during 10-20 min for each condition shown in panels ( $i$ and j), which were tested with a one-way ANOVA and post hoc Tukey's multiple comparisons test. In panel (i): ${ }^{\#} p<0.000$ I and ${ }^{*} * * * p<0.00$ I relative to vehicle control, ${ }^{\$} p<0.00$ I and ${ }^{\times} p<0.000$ I for bicuculline in LPO (closed circles, min 10-20) vs bicuculline in RMTg and LPO (closed squares, I0-20 min). In panel (j): ${ }^{*} p<0.000$ I and **** $p<0.00$ I relative to vehicle; ${ }^{\times} p<0.000$ I relative to bicuculline in LPO (closed circle). Scale bar $-400 \mu \mathrm{m}$.

\section{RMTg Effect on Conditioned Locomotion}

Conditioning protocol. Amphetamine-conditioned and control groups were generated by administering to rats, every other day for five sessions, i.p. injections, respectively, of D-amphetamine $(1 \mathrm{mg} / \mathrm{kg})$ or an equivalent volume of saline and placing them in activity monitors for $60 \mathrm{~min}$. The rats were habituated to the behavior testing room for at least $20 \mathrm{~min}$ prior to each training session, and locomotion was measured as described above.

Placement of guide cannulae. One day after the final conditioning session, rats were deeply anesthetized and guide cannulae were implanted into the brain bilaterally above the RMTg as described above.

Blockade of conditioned locomotion by disinhibition of the RMTg. One week following placement of cannulae, the rats were subjected to one additional amphetamine conditioning session and, the following day, tested as follows. Rats in the unconditioned control group $(n=5)$ received bilateral infusions of vehicle into the RMTg and an i.p. injection of saline and were placed in the activity monitors. Amphetamine-conditioned rats were split into two groups, of which rats in one group received bilateral infusions of vehicle $(n=7)$ and in the other bicuculline $(n=5)$ into the RMTg, after which all were given i.p. vehicle injections and placed in the activity monitors. Distance traveled was recorded for $20 \mathrm{~min}$.

Extinction training and control infusions. The rats then were placed in the activity monitors with no injections for 20 min several times daily until amphetamine-conditioning was extinguished, as determined by loss of group differences in distance traveled. Then, on separate successive 
days, they received RMTg infusions of saline, bicuculline, or muscimol, after which distance traveled was recorded for $20 \mathrm{~min}$.

\section{Fixation of Brains and Staining}

The rats were deeply anesthetized as described previously and perfused transaortically with $0.01 \mathrm{M}$ Sorenson's phosphate buffer (SPB; pH 7.4) containing $0.9 \%$ sodium chloride and $2.5 \%$ sucrose, followed by $0.1 \mathrm{M} \mathrm{SPB} \mathrm{(pH} \mathrm{7.4)} \mathrm{contain-}$ ing $4 \%$ paraformaldehyde and $2.5 \%$ sucrose. The perfused brains were removed and placed in the same fixative for $4 \mathrm{~h}$ and then in a $30 \%$ sucrose solution overnight. Parts of the brains containing the injection sites were sectioned in series of three adjacent 50- $\mu \mathrm{m}$ thick sections using a cryostat, the first of which was thaw-mounted on subbed glass slides. The mounted sections were placed overnight in a $1: 1$ mixture of absolute alcohol and chloroform, rehydrated, stained in a solution of $0.1 \%$ cresyl violet in acetic acid $(\mathrm{pH}$ 3.5) for $15 \mathrm{~min}$, dehydrated, placed in xylene, and coverslipped with Permount.

\section{Analysis of Data}

Counts of infrared beam breaks reflecting distance traveled were partitioned into 2-min bins. Binned data were tested with a two-way ANOVA (distance $\times$ time) and validated post hoc with Tukey's test for multiple comparisons. Total distance was tested with a one-way ANOVA and post hoc Tukey's multiple comparison's test. Total distance was compared between D-amphetamine-conditioned and unconditioned groups during the conditioning trials using a two-way ANOVA and Sidak's multiple comparison's test. The critical limit was set at $p<0.05$ for all experiments.

\section{Maps of Infusion Sites}

Mapping of the locations of the tips of injectors was done under brightfield optics with the aid of an Olympus BX51 microscope and the Neurolucida dedicated hardwaresoftware platform (MBF Bioscience, Williston, VT). Areas corresponding to the VTA/SNc and RMTg were defined on the diagrams of the Nissl-stained sections by superimposing on them, with the aid of Adobe Illustrator software, outlines traced with the Neurolucida system from sections cut in the same plane and at the same level and processed to exhibit tyrosine hydroxylase immunoreactivity for the VTA/SNc (see Zahm et al, 2013) and Fos immunoreactivity following administration of D-amphetamine (see Jhou et al, 2009b).

\section{RESULTS}

\section{RMTg Muscimol and VTA Bicuculline Infusions Produce Vigorous Locomotor Activation}

Micrographs illustrating representative unilateral and bilateral infusion sites in the LPO, RMTg, and VTA are shown in Figures 1a, b, and 2a, respectively, and additional infusion sites are mapped in Figure 1c-e (LPO), Figure $1 \mathrm{f}-\mathrm{h}$ (RMTg), and Figure 2b-d (VTA). Muscimol infused bilaterally into the RMTg produced robust locomotor activation as compared with vehicle (Figure 1i, 10-20 min, diamonds $v s$ open circles, and Figure 1j). A two-way ANOVA test of data shown in Figure 1i revealed significant main effects of drug $\left(\mathrm{F}_{4,30}=18.49, p<0.0001\right)$ and time $\left(\mathrm{F}_{5,150}=4.732, p=0.0005\right)$ and a significant interaction between drug and time $\left(\mathrm{F}_{20,150}=4.420, p<0.0001\right)$. Post hoc testing of these data revealed significant differences in all bins from 10 to $20 \mathrm{~min}$ ( $10 \mathrm{~min}: t_{180}=6.4270, p<0.0001$; $12 \mathrm{~min}: t_{180}=6.4160, \quad p<0.001 ; 14 \mathrm{~min}: t_{180}=6.2560$, $p<0.001 ; 16 \mathrm{~min}: t_{180}=6.1140, p<0.001 ; 18 \mathrm{~min}: t_{180}=$ $\left.6.3850, p<0.001 ; 20 \mathrm{~min}: t_{180}=6.1550, p<0.001\right)$. Associated total distance (Figure 1j) was tested by one-way ANOVA, which revealed a significant main effect of drug $\left(\mathrm{F}_{4,30}=18.49, p<0.0001\right)$, and the post hoc comparison of muscimol $v s$ saline infusions into RMTg (Figure $1 \mathrm{j}$, diamond $v s$ open circle) showed a significant difference $\left(t_{30}=6.661 ; p<0.001\right)$. In contrast, following bilateral bicuculline infusions into the RMTg, locomotion was not different than vehicle controls (Figure 1i, 2-6 min, open circles $v s$ open squares) The test of these data (two-way ANOVA, 2-6 min) revealed a non-significant effect of drug $\left(\mathrm{F}_{4,30}=0.7874\right.$, not significant $)$, but a significant effect of time $\left(\mathrm{F}_{2,60}=36.44, p<0.0001\right)$ and a significant interaction between drug and time $\left(\mathrm{F}_{8,60}=2.448, p=0.0231\right)$, whereas post hoc testing revealed no significant differences at any time points ( $2 \mathrm{~min}: t_{90}=2.395$, not significant; $4 \mathrm{~min}$ : $t_{90}=0.9520$, not significant; 6 min: $t_{90}=0.7837$, not significant). Pooling of the two bicuculline (Figure 1i, 2-6 min, open and closed squares) and two vehicle (Figure 1i, 2-6 min, open and closed circles) also produced a nonsignificant effect of drug $\left(\mathrm{F}_{1,25}=0.8932, p=0.3537\right)$, significant effect of time $\left(\mathrm{F}_{2,50}=23.42, p<0.0001\right)$, and significant interaction $\left(\mathrm{F}_{5,50}=7.751, p=0.0012\right)$. Because the nonsignificant drug effect may have been due to a floor phenomenon, the pooled data were subjected to post hoc testing, which revealed a significant difference between the bicuculline and vehicle groups at the 2-min time point (Figure 1i, 2-6 min, open and closed circles $v s$ open and closed squares; $2 \mathrm{~min}: t_{75}=2.945, p<0.05 ; 4 \mathrm{~min}$ : $t_{75}=0.3803$, not significant; $6 \mathrm{~min}: t_{75}=0.1925$, not significant).

Alternatively, bilateral bicuculline infusions into the VTA strongly activated locomotion relative to vehicle (Figure $2 \mathrm{e}$ and $\mathrm{f}$, closed $v s$ open circles). A two-way ANOVA test of data shown in Figure 2e revealed significant main effects of drug $\left(\mathrm{F}_{2,21}=43.24, p<0.0001\right)$ and time $\left(\mathrm{F}_{9,189}=25.47\right.$, $p=0.0005)$ and a significant interaction between them $\left(\mathrm{F}_{18,189}=4.1888, p<0.0001\right)$. Post hoc testing of data from bicuculline $v s$ vehicle infusions into the VTA revealed significant differences in all bins from 2 to $20 \mathrm{~min}(2 \mathrm{~min}$ : $t_{210}=6.0040, p<0.0001 ; 4 \mathrm{~min}: t_{210}=8.8800, p<0.0001$; $6 \mathrm{~min}: t_{210}=10.5400, \quad p<0.0001 ; 8 \mathrm{~min}: t_{210}=9.9290$, $p<0.0001 ; \quad 10 \mathrm{~min}: \quad 210=10.6600, \quad p<0.0001 ; \quad 12 \mathrm{~min}$ : $210=9.7140, p<0.0001 ; 14 \mathrm{~min}: 210=8.4160, p<0.0001$; $16 \mathrm{~min}: t_{210}=6.9060, \quad p<0.0001 ; \quad 18 \mathrm{~min}: t_{210}=4.7640$, $p<0.01 ; 20$ min: $\left.t_{210}=5.0720, p<0.01\right)$. Associated total distance (Figure 2f) was tested by one-way ANOVA, which revealed a significant main effect of drug $\left(\mathrm{F}_{2,21}=40.47\right.$, $p<0.0001$ ) and post hoc comparison between bicuculline $v$ s vehicle infusions into the VTA $\left(t_{21}=10.67 ; p<0.0001\right)$. Muscimol infused bilaterally into the VTA produced locomotion no different than following vehicle infusions (Figure 2e, squares $v s$ open circles) as revealed in post hoc 

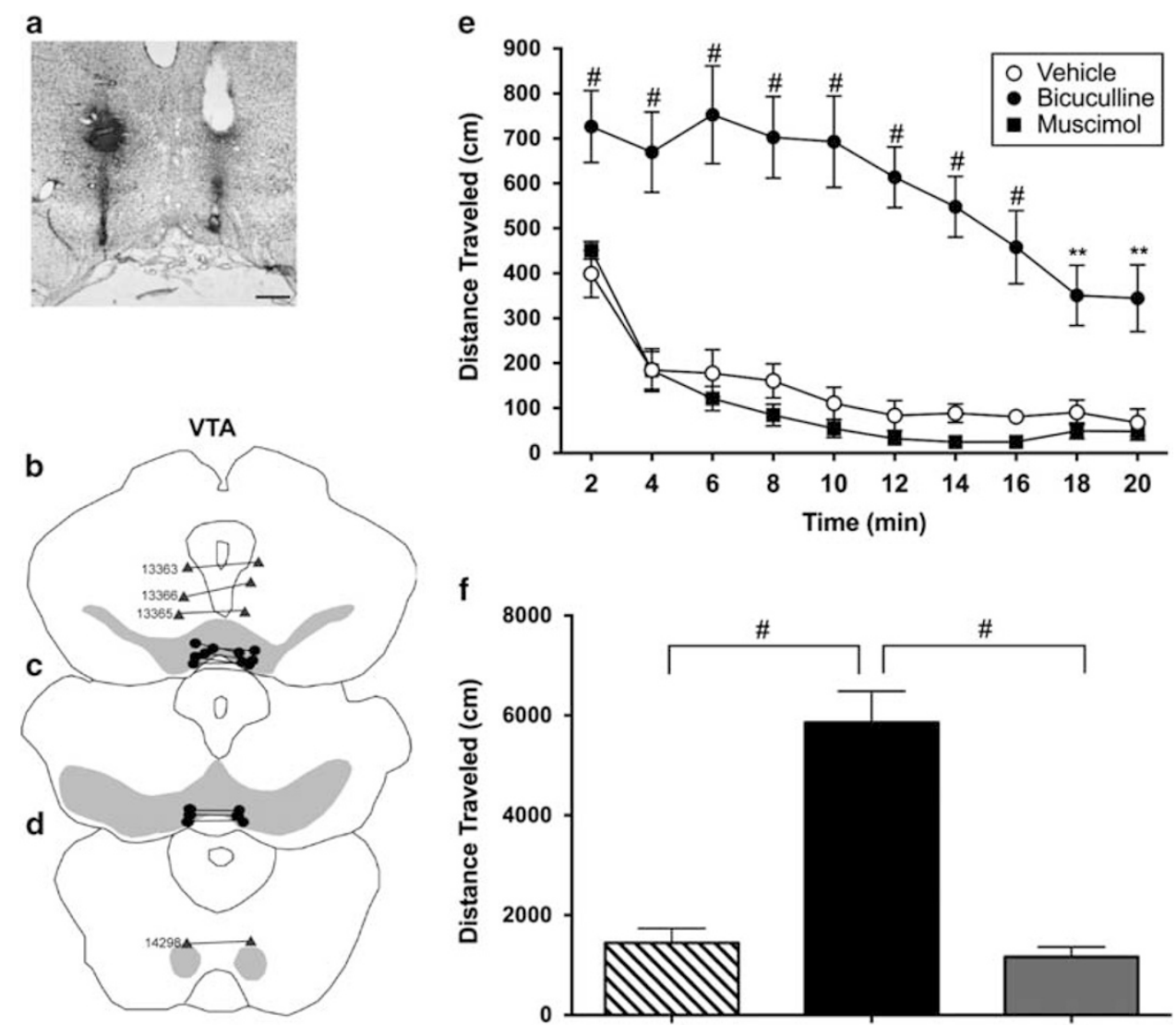

f

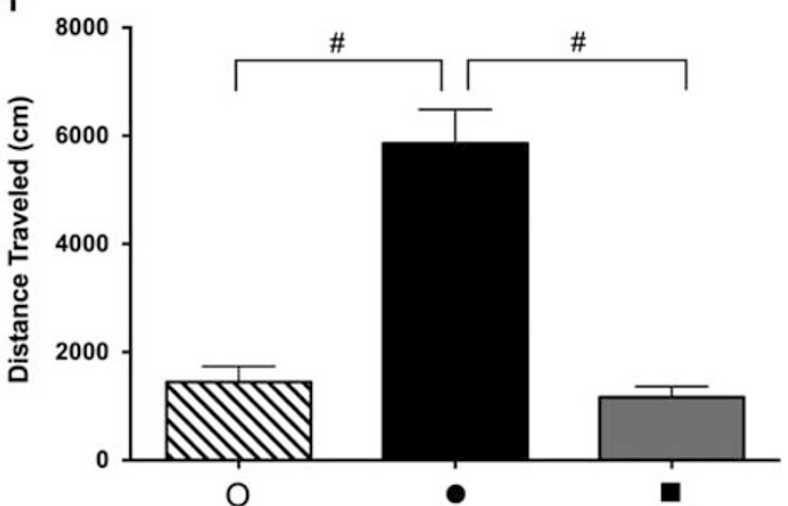

Figure 2 (a) Nissl-stained section of brain showing representative bilateral cannula placements into the VTA. (b-d) Diagrams of series of sections ordered from rostral (top) to caudal (bottom) showing infusion sites. The gray shading in the sections illustrates the approximate boundaries of the VTA (b and c) and RMTg (d). Black dots indicate on-target infusion sites; gray triangles indicate off-target sites and are identified by the corresponding case numbers. (e) Distance traveled following infusions of vehicle, muscimol or bicuculline into the VTA. For all conditions, $n=8$. Distance traveled was recorded in 2-min bins for a total of $20 \mathrm{~min}$ and analyzed with a two-way ANOVA (distance $\times$ time) with post hoc Tukey's multiple comparison's test. ( $f$ ) Graph showing total distances traveled for each condition shown in panel (e), which were tested with a one-way ANOVA and post hoc Tukey's multiple comparisons test. In panel (e): ${ }^{* *} p<0.01$ and ${ }^{\#} p<0.000$ I relative to vehicle. In panel (f): ${ }^{\#} p<0.000$ I. Scale bar $-400 \mu \mathrm{m}$.

testing of the binned data in Figure $2 \mathrm{e}$ (all non-significant2 min: $t_{210}=0.9608 ; 4$ min: $t_{210}=0.0092 ; 6$ min: $t_{210}=1.024$; $8 \mathrm{~min}: t_{210}=1.392 ; 10 \mathrm{~min}: t_{210}=1.028 ; 12 \mathrm{~min}: t_{210}=$ 0.9424 ; $14 \mathrm{~min}: t_{210}=1.173 ; 16 \mathrm{~min}: t_{210}=1.022 ; 18 \mathrm{~min}$ : $\left.t_{210}=0.7550 ; 20 \mathrm{~min}: t_{210}=0.3559\right)$ and data for total distance $\left(t_{21}=0.6724\right.$, not significant $)$.

\section{RMTg Bicuculline Infusions Block LPO-Induced Locomotion}

Unilateral infusion of bicuculline as compared with vehicle into the LPO produced robust locomotor activation (Figure 1i, 10-20 min, closed vs open circles, and Figure $1 \mathrm{j}$ ). The binned data were tested by two-way ANOVA (as reported above), and the results of the associated post hoc tests for bicuculline as compared with vehicle infused into the LPO are as follows: $10 \mathrm{~min}: t_{180}=9.1270, p<0.0001$; $12 \mathrm{~min}: t_{180}=10.9100, \quad p<0.0001 ; 14 \mathrm{~min}: t_{180}=9.8710$, $p<0.0001 ; \quad 16 \mathrm{~min}: \quad t_{180}=8.4040, \quad p<0.0001 ; 18 \mathrm{~min}:$ $t_{180}=7.0180, p<0.0001 ; 20 \mathrm{~min}: t_{180}=6.4890, p<0.0001$. The associated total distance data (Figure $1 \mathrm{j}$ ) were tested by one-way ANOVA (as reported above) and the comparison between bicuculline and vehicle infused into the LPO was found to be significantly different $\left(t_{30}=9.144 ; p<0.0001\right)$. Locomotion produced by infusions of bicuculline into the LPO was blocked by infusion of bicuculline into the RMTg (Figure 1i, 10-20 min, closed squares vs closed circles, as revealed by the post hoc tests- $10 \mathrm{~min}$ : $t_{180}=8.7320, p<0.0001 ; 12 \mathrm{~min}: t_{180}=10.5400, p<0.0001$; $14 \mathrm{~min}: \quad t_{180}=9.6440, \quad p<0.0001 ; 16 \mathrm{~min}: t_{180}=8.0380$, $p<0.0001 ; \quad 18 \mathrm{~min}: \quad t_{180}=6.8860, \quad p<0.0001 ; \quad 20 \mathrm{~min}:$ $\left.t_{180}=5.9850, p<0.001\right)$, ie, not different than controls (Figure 1i, 10-20 min, closed squares vs open circles; all nonsignificant $-10 \mathrm{~min}: t_{180}=0.5528 ; 12 \mathrm{~min}: t_{180}=0.1073$; $14 \mathrm{~min}: \quad t_{180}=0.4155 ; \quad 16 \mathrm{~min}: \quad t_{180}=0.3752 ; \quad 18 \mathrm{~min}$ : $\left.t_{180}=0.0032 ; 20 \mathrm{~min}: t_{180}=0.3276\right)$. Associated total distance data (Figure $1 \mathrm{j}$, closed square $v$ s closed circle) likewise revealed that locomotion produced by bicuculline in the LPO is significantly suppressed by infusion of bicuculline into the RMTg $\left(t_{30}=8.829 ; p<0.0001\right)$, resulting in locomotion not different than observed following LPO vehicle (Figure $1 j$, closed square $v s$ open circle, $t_{30}=0.3144-$ not significant). Bicuculline infusions into the RMTg as compared with the LPO (Figure $1 \mathrm{i}$ and $\mathrm{j}, 10-20 \mathrm{~min}$, closed circles $v s$ open squares) were also associated with significantly less locomotion as revealed by the binned data 


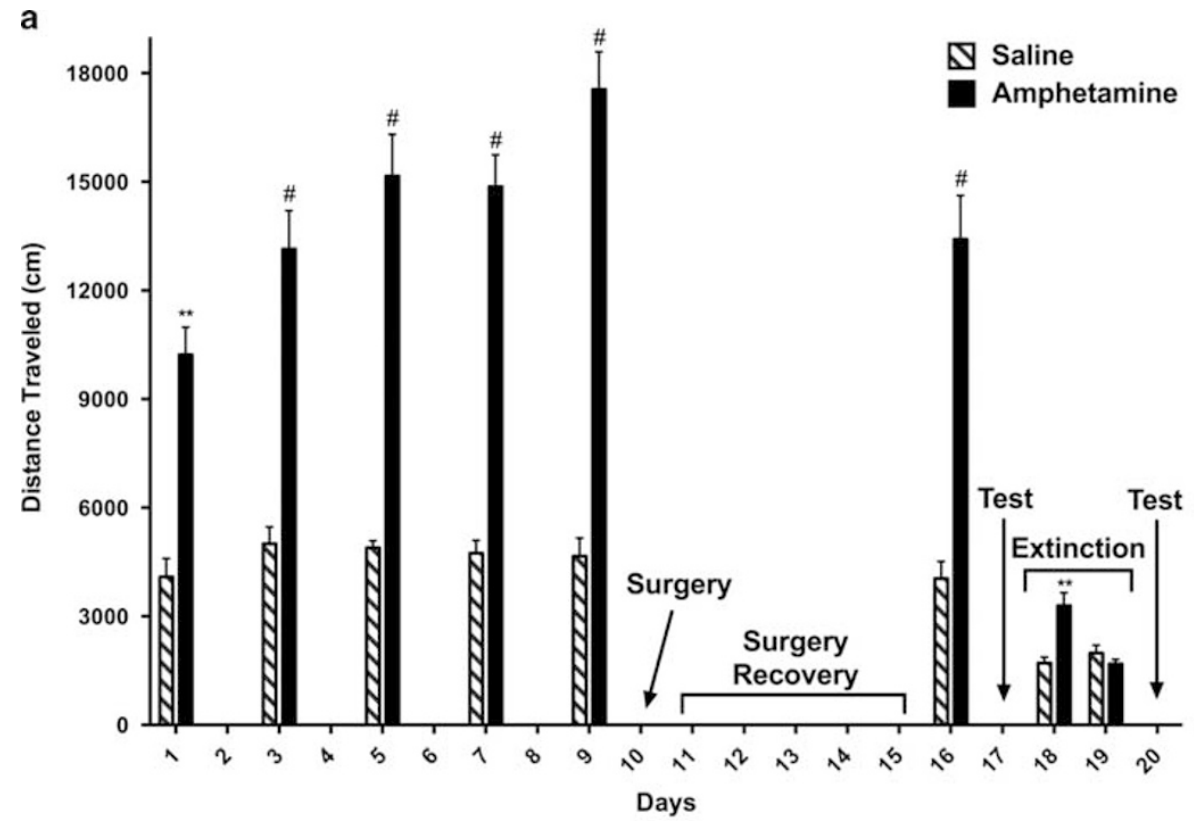

b

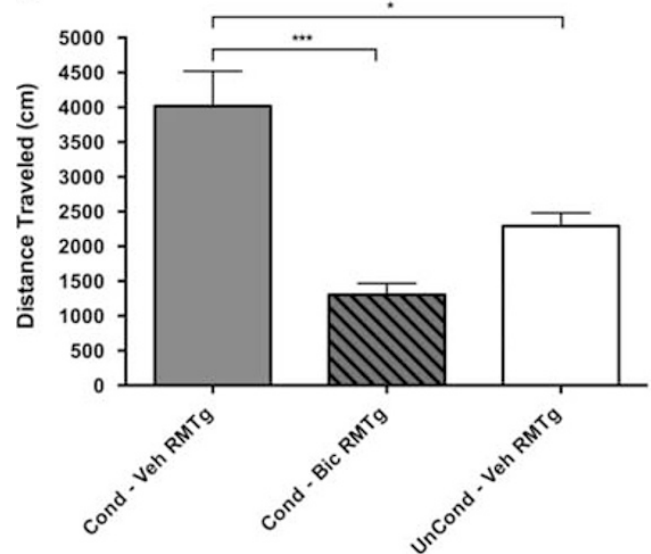

C

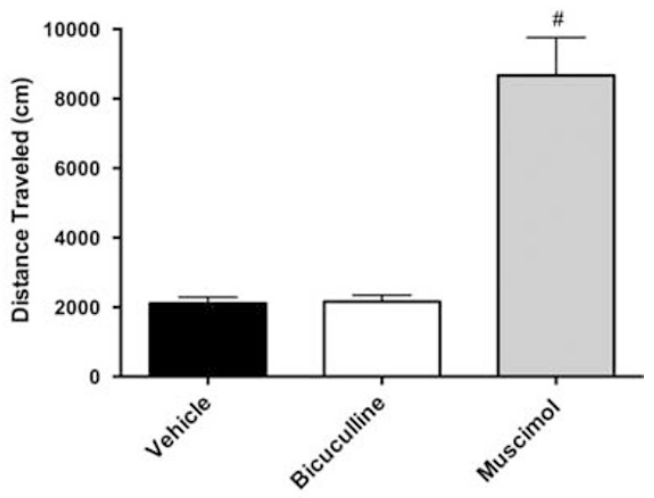

Figure 3 (a) Diagram depicting the conditioned locomotion experimental protocol. Amphetamine-conditioned and unconditioned rats were generated by administering i.p. injections of either D-amphetamine $(\mathrm{lmg} / \mathrm{kg})$ or an equivalent volume of saline and placing them in activity monitors for 60 min every other day for five sessions (days I, 3, 5, 7, and 9). One day after the final conditioning session, cannulae were surgically implanted (day I0, 'Surgery'), and after I week of recovery (Days I I-15, 'Surgery Recovery') the rats received an additional amphetamine-conditioning session on Day I6 and were tested the following day (Day 17, 'Test'). During the next 2 days, the amphetamine conditioning was extinguished until distance traveled for 20 min was no different between groups (Days 18-19, 'Extinction') then on separate days, beginning on day 20, the rats received RMTg infusions of saline, bicuculline, and muscimol and were again tested (Day 20, 'Test'). Data were tested with a two-way ANOVA and post hoc Sidak's multiple comparison's test. \# $p<0.000$ I and *** $p<0.0$ I relative to the saline-injected control group. (b) Data from the testing done on day 17. Rats in the unconditioned group ( $n=5)$ were given bilateral infusions in the RMTg of vehicle $(0.125 \mu \mathrm{l})$, and an i.p. injection of saline, and placed in the activity monitors. Amphetamine-conditioned rats were split into two groups, of which rats of one received bilateral infusions of vehicle $(n=7)$ and of the other, bicuculline $(n=5)$, into the RMTg, after which all were given i.p. saline and placed in the monitors. Distance traveled was recorded during $20 \mathrm{~min}$. (c) Distance traveled after infusions of saline, bicuculline, or muscimol into the RMTg on separate days, beginning on Day 20. Total distance traveled was recorded for 20 min. Data in panels (b and c) were tested with a one-way ANOVA and post hoc Tukey's multiple comparisons test. In panel (b): ${ }^{*} p<0.05$ and $* * * p<0.00$ I. In panel (c): ${ }^{*} p<0.000$ I relative to vehicle.

(10 min: $\quad t_{180}=8.574, \quad p<0.0001 ; \quad 12 \mathrm{~min}: \quad t_{180}=10.80$, $p<0.001 ; 14 \mathrm{~min}: t_{180}=9.456, p<0.001 ; 16 \mathrm{~min}: t_{180}=8.029$, $p<0.001 ; 18$ min: $t_{180}=7.015, p<0.001 ; 20$ min: $t_{180}=6.1620$, $p<0.001)$ and total distance $\left(t_{30}=8.792 ; p<0.001\right)$.

\section{RMTg Bicuculline Infusions Block Conditioned Locomotion}

Rats that received i.p. D-amphetamine as compared with vehicle injections during conditioning training exhibited significantly greater locomotor activation during all conditioning days (Figure 3a). Testing of the relevant data by two-way ANOVA revealed significant main effects of drug $\left(\mathrm{F}_{1,15}=60.97, p<0.0001\right)$ and time $\left(\mathrm{F}_{5,75}=4.903\right.$, $p=0.0006)$ and a significant interaction between them $\left(\mathrm{F}_{5,75}=3.496, p=0.0068\right)$. Post hoc testing of the data revealed significant differences on all test days (Day 1: $t_{90}=3.730, p<0.01$; Day 3: $t_{90}=4.950, p<0.0001$; Day 5: $t_{90}=6.245, p<0.0001$; Day 7: $t_{90}=6.156, p<0.0001$; Day 9: $t_{90}=7.845, p<0.0001$; Day 16: $\left.t_{90}=5.700, p<0.0001\right)$ and in 
the test session (Figure $3 \mathrm{~b}$ ) after being given an i.p. vehicle injection (one way ANOVA-main effect of drug: $\mathrm{F}_{2,14}=13.34 ; p=0.0006$; post hoc test: $t_{14}=4.520, p<0.05$ ), which was regarded as evidence that conditioned locomotion had been established. The conditioned locomotor response was blocked by infusion of bicuculline (Figure 3b; $\left.t_{14}=7.101, p<0.001\right)$ but not vehicle $\left(t_{14}=2.390\right.$, not significant) into the RMTg. After 2 days, when the conditioned locomotor response had been extinguished by exposing the rats to the activity monitors during daily multiple trials without administering $\mathrm{D}$-amphetamine injections (Figure 3a; Day 18: $t_{30}=3.578, p<0.001$; Day 19: $t_{30}=0.6811$, not significant), robust locomotor activation produced by RMTg muscimol, as compared with vehicle (Figure 3c; one-way ANOVA main effect of drug: $\mathrm{F}_{2,48}=33.91 ; p<0.0001 ;$ post hoc test $\mathrm{t}_{48}=10.12, p<0.0001$ ) but not bicuculline infusions ( $t_{48}=0.07596$, not significant) was taken as verification of effective RMTg infusion sites.

\section{Off-Target Infusions}

Two rats had guide cannulae targeted to the RMTg of which one of the two was misplaced rostrally relative to the other (Figure $1 \mathrm{~g}$ and $\mathrm{h}$, cases 13377 and 13 379). After receiving infusions of vehicle containing bicuculline, these rats circled toward the side with the more caudally placed cannula. Another rat in which cannulae targeted to the RMTg were slightly misplaced rostrodorsally (Figure 1g, case 13417) circled to the left following infusions of vehicle containing muscimol. Six rats had guide cannulae targeted to the RMTg but misplaced rostrally such that the injections involved the rostral pole of the RMTg, which occupies the caudal extremity of the VTA (Jhou et al, 2009b). Four of these rats (cases 13330,13378, 13380, and 13418) exhibited increased locomotion after receiving infusions of vehicle containing bicuculline and two (cases 13333 and 14053) had no change in locomotion relative to baseline (Figure if and g). Two rats with cannulae targeted to the RMTg, but misplaced dorsally near the ventral periaqueductal gray and dorsal raphe (Figure 1g, cases 14079 and 14080 ), showed no change in locomotion compared with baseline after receiving infusions of vehicle containing muscimol. Three rats with cannulae targeted to the VTA but misplaced dorsally (Figure 2b, cases 13363,13365 , and 13366) showed no change in locomotion compared with baseline after receiving infusions of vehicle containing bicuculline or muscimol, and one case misplaced caudally (Figure $2 \mathrm{~d}$ case 14298 ) had an increase in locomotion compared with baseline after receiving infusions of vehicle containing muscimol. Five rats with cannulae targeted to the LPO were misplaced dorsally and laterally (Figure 1c and d, cases 13 377, 13 379, 13380,14021 ) showed no change in locomotion compared with baseline after receiving infusions of vehicle containing bicuculline, consistent with previous studies (Zahm et al, 2014).

\section{DISCUSSION}

\section{Methodological Considerations}

The use of microinfusions to elicit changes in locomotor behavior has significant methodological limitations, due, eg, to uncertainties regarding variable spread of the drug and the kinds of neurons affected. To minimize spread of the LPO infusions, we used a modest $0.25-\mu \mathrm{l}$ infusion volume consistent with previous work (Zahm et al, 2014) and sufficient to elicit robust locomotor activation. Bilateral infusions into the RMTg were also initially made at $0.25 \mu \mathrm{l}$, but this occasionally caused erratic propulsive behaviors, which were minimized by reducing RMTg and VTA infusion volumes to $0.125 \mu \mathrm{l}$ per side. In a few cases, infusions into the RMTg resulted in circling, sometimes on some test days but not others, which may have reflected unequal activations of the RMTg on the two sides of the midline possibly due to obstruction, perhaps by brain or vascular tissue, of one of the injection cannulae. Unequal activity in the substantia nigra compacta, but not VTA, on the two sides of the midline is well established as a cause of such rotational behavior (Tarsy et al, 1975; Kelly and Moore, 1976; Mogenson et al, 1979; Bourdy et al, 2014). Insofar as the RMTg projects strongly to both the VTA and SNc (Jhou et al, 2009a, b; Bourdy et al, 2014), it is likely that the rotational behavior occasionally observed in this study was due to asymmetry involving RMTg effects in the SNc. Occasional obstruction of the injection cannulae may also explain observed intra-subject variability in locomotor activation on different test days. An other unexpected finding - that bicuculline infused into the RMTg did not reduce locomotor activity below baseline-likely reflects a 'floor' phenomenon, ie, that the baseline locomotion of rats habituated to the test chambers was sufficiently low as to preclude statistically valid measurement of a lesser amount. This notion is supported by the observation that pooled data at the 2-min time point, when the rats were more active, did reveal a significant reduction of basal locomotor activity by bicuculline infusions into the RMTg (Figure 1i). Another factor that may impede observation of profound inhibition of locomotion following RMTg bicuculline infusions is that some RMTg infusions might result in some spread of bicuculline into the VTA, disinhibition of which would oppose the behavioral effect of drug acting in the RMTg (Figure 2 and Mogenson et al, 1979).

Overall, the critical effects reported here were maximized and variable ones minimized by appropriate infusion volumes and infusion cannulae properly positioned with respect to the locations of the RMTg, VTA and LPO. The data are further strengthened by the opposite effects on locomotion of infusions into the RMTg and nearby VTA. Thus, the conclusions reported herein are stated with confidence, even taking into consideration the complex organization of the ventral mesencephalic tegmentum (Yetnikoff et al, 2014) and LPO (Kowski et al, 2008).

\section{General Discussion}

As the RMTg gained recognition as a distinct structure (Jhou, 2005; Jhou and Gallagher, 2007; Jhou et al 2009a, b; Perrotti et al, 2005; Kaufling et al, 2009, 2010), its capacity to control the activity of midbrain DA neurons (Hong et al, 2011; Matsui and Williams, 2011; Lecca et al, 2011, 2012; Matsui et al, 2014) and the implications of this action in aversion (Jhou et al, 2009b), reward (Hong et al, 2011), and neurobiological responses to certain drugs of abuse (Matsui and Williams, 2011; Lecca et al, 2011, 2012; Jhou et al, 2013; 
Wasserman et al, 2013; Matsui et al, 2014) continue to concern investigators. Despite this wealth of interest, a fundamental behavior-locomotor activation-has been overlooked, yet we show here that modulation of RMTg activity has profound effects on locomotion. Our microinfusions indicate that suppression of RMTg activity produces vigorous locomotor activation, whereas activation of the RMTg suppresses not only locomotor activation associated with pharmacological stimulation (disinhibition) of the LPO but also conditioned locomotor activation, which is a more natural effect, presumably driven by an internal affective state, ie, anticipation (references provided in Introduction section).

Locomotor-activating effects of RMTg inhibition were previously hinted at by Jhou et al (2009a), who reported on the scoring of rats with cell-depleting lesions of the RMTg for responses to fear-related behaviors. They showed that such lesions were associated with reduced conditioned freezing in the presence of cues signaling foot shock, reduced unconditioned freezing in the presence of 2,4,5 dihydro 2,5 trimethylthiazoline, a predator odor, and increased exploratory entries to the open-arms of the plus maze, of which all reflect impaired passive suppression of locomotion. In contrast, RMTg lesions had no effect upon, nor even trended toward enhancement of active fear behaviors, such as treading or escaping. Although Jhou et al (2009a) did not detect significant increases in baseline locomotion compared with control following such lesions, their results support strong RMTg effects on specific types of locomotor-related responding in fear-eliciting circumstances. Moreover, their results show that the effects of RMTg lesions oppose those associated with dopamine depletion, which impairs active, but enhances passive, fear behaviors (Lenard and Beer, 1975; Jhou et al, 2009a).

LPO stimulation. LPO stimulation (disinhibition) was used in the present study as an artificial experimental expedient to elicit locomotor activation. The LPO is a wellestablished site where robust locomotor activation can be elicited by infusions of $\mathrm{GABA}_{\mathrm{A}}$ antagonists, such as picrotoxin (Shreve and Uretsky, 1988; 1991; Austin and Kalivas, 1990; 1991) and bicuculline (Reynolds et al, 2006; Zahm et al, 2014), and glutamatergic receptor agonists (Shreve and Uretsky, 1988, 1989, 1991; Willins et al, 1992). Locomotion elicited by stimulating (or disinhibiting) the LPO and certain adjacent forebrain areas such as the ventral pallidum (see Zahm et al, 2014) is suppressed by systemic injections of dopamine antagonists (Austin and Kalivas, 1991; Kalivas et al, 1991; Johnson et al, 1996; Zahm et al, 2011) and by infusion of dopamine antagonists directly into the Acb (Austin and Kalivas, 1991; Kalivas et al, 1991; Johnson et al, 1996), indicating that the expression of this behavior is dependent upon intact mesoaccumbal dopaminergic neurotransmission. LPO-elicited locomotor activation is also suppressed by bilateral infusions into the VTA of an antagonist to the neurotensin 1 receptor (Reynolds et al, 2006), which, in the midbrain, is selectively enriched on dopamine neurons (Quirion et al, 1985; Woulfe and Beaudet, 1989; Bayer et al, 1991) and excites them (Seutin et al, 1989; Shi and Bunney, 1991; Litwin and Goldstein, 1994; Sotty et al, 2000; Werkman et al, 2000), causing dopamine release in the Acb (Blaha et al, 1990; Seutin et al, 1989; Kalivas and Duffy, 1990; Laitinen et al, 1990; Sotty et al, 2000), which further implicates impairment specifically of the VTA-Acb dopaminergic pathway as a critical impediment to locomotor activation. Alternatively, locomotion elicited by administration of psychostimulant drugs, such as D-amphetamine, which increase the levels of dopamine in the Acb, is suppressed by infusion of muscimol into the LPO and ventral pallidum (Austin and Kalivas, 1989; Zahm, unpublished observations), indicating that co-activation (or disinhibition) of the LPO and mesoaccumbal dopaminergic neurons is essential to locomotor activation, as also must be, presumably, downstream projections to motor effectors (Mogenson et al, 1985; Holstege, 1991).

Thus it should be no surprise that LPO-elicited locomotor activation is suppressed by bicuculline infusions into the RMTg, inasmuch as disinhibiting the RMTg enables it to more powerfully inhibit midbrain dopamine neurons (Jhou et al, 2009a, 2013; Hong et al, 2011; Lecca et al, 2011, 2012; Matsui and Williams, 2011; Wasserman et al, 2013). A more difficult issue to contemplate is how the LPO so efficiently elicits locomotion, presumably through the actions of direct projections to the VTA (Phillipson, 1979; Zahm et al, 2001; Geisler and Zahm, 2005, 2006; Reynolds et al, 2006; Geisler et al, 2007), when LPO also projects strongly to the RMTg (Jhou et al, 2009b; Kaufling et al, 2009; Zahm et al, 2011), which, as we repeatedly emphasize, directly inhibits the VTA. The conundrum presented by this arrangement of connections is reconciled if output from the LPO (1) inhibits VTA-projecting RMTg neurons, which serves to disinhibit midbrain dopaminergic neurons, and (2) the same LPO output selectively targets inhibitory neurons in the VTA - to the same effect. Indeed, in a recent study (Lavezzi et al, 2013), we determined that significant numbers of LPO neurons project by way of axon collaterals to both the VTA and RMTg, causing us to hypothesize that single GABAergic outputs from the LPO selectively target GABA neurons in the RMTg and VTA, which, in turn, converge upon and, upon LPO activation, efficiently disinhibit VTA dopamine neurons-resulting in locomotor activation. If this hypothesis (Figure 4) is correct, GABAergic LPO outputs can convert the RMTg to a facilitator of midbrain dopaminergic activity, complementing its better known role as a dopaminergic suppressor (Barrot and Thome, 2011; Bourdy and Barrot, 2012) in response mainly (at least as is known so far) to input from the lateral habenula (Jhou et al, 2009a, b). Unfortunately, aside from glutamatergic (Geisler et al, 2007) and neurotensinergic (Zahm et al, 2001; Geisler and Zahm, 2006) projections to the VTA, the phenotypes of LPO outputs to the mesopontine tegmentum, and their projection specificities remain to be revealed.

Conditioned locomotion. Because stimulating a brain structure to elicit locomotor behavior does not represent a physiological scenario that exists in nature, we also wanted to look at whether disinhibition of RMTg neurons would also block conditioned locomotion, which is elicited by an environment in which repeated exposures to amphetamine had previously occurred (references in the Introduction section) and which arises purely from the internal state of 


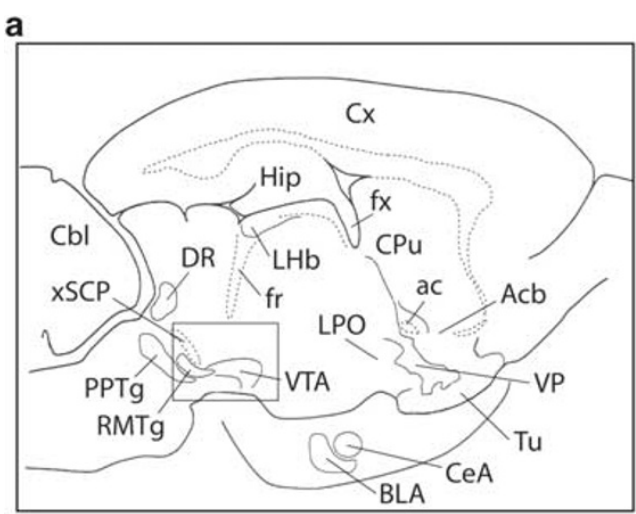

b

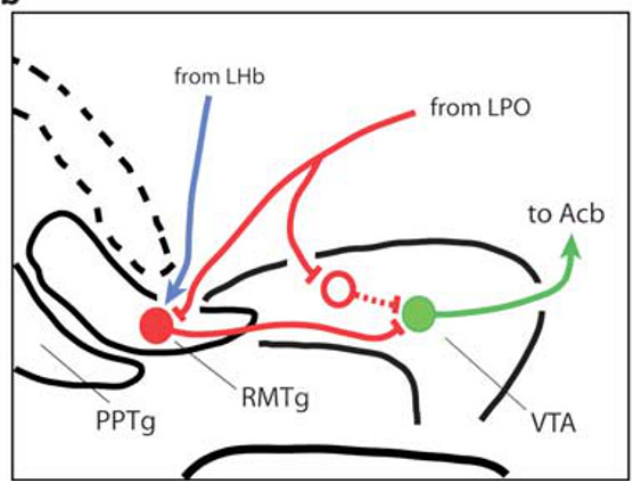

Figure 4 Diagram illustrating the hypothesized connectivity by which lateral preoptic area (LPO) activation produces activation of mesoaccumbal dopaminergic neurotransmission and accompanying locomotor activation. Panel (a) illustrates a slightly upward tilted sagittal section through the rat brain showing the location of the rostromedial tegmental nucleus (RMTg) and ventral tegmental area (VTA) in relation to numerous other brain structures. Panel (b) is an enlargement of the boxed area in panel (a) showing the hypothesized circuitry. A branched GABAergic projection (red line) from the LPO contacts a GABAergic neuron (red dot) in the RMTg and a postulated GABAergic neuron in the VTA (red circle), which have axons (red lines) that converge to contact a dopaminergic neuron in the VTA (green dot and line) that projects to the accumbens (Acb). Activation of the LPO GABAergic axon inhibits the convergent inhibitory projections from the RMTg and VTA to the dopaminergic neuron. The blue line depicts a glutamatergic projection from the lateral habenula $(\mathrm{LHb})$ to the RMTg, which would drive an inhibition of the dopaminergic VTA neuron. ac, anterior commissure; BLA, basolateral amygdala; Cbl, cerebellum; CeA, central nucleus of the amygdala; CPu, caudate-putamen; $\mathrm{Cx}$, cerebral cortex; DR, dorsal raphe nucleus; fx, fornix; Hip, hippocampus; PPTg, pedunculopontine tegmental nucleus; Tu, olfactory tubercle; VP, ventral pallidum; XSCP, decussation of the superior cerebellar peduncle.

the animal's brain rather than unnatural investigator manipulation. We predicted and have demonstrated herein that activation of the RMTg prevents the expression of conditioned locomotion, and we suggest that this effect is mediated by RMTg inhibitory projections to VTA DA neurons. This notion is consistent with the connections of the RMTg (references given above) and the existing functional literature. To wit, conditioned locomotion was blocked by both preconditioning and postconditioning administration of dopamine-depleting lesions of the Acb (Gold et al, 1988) and systemic treatment with DA antagonists (Beninger and Hahn, 1983; Gold et al, 1988), of which all attenuate or abolish mesolimbic DAergic neurotransmission in the Acb. In rats with intact mesoaccumbal DA innervation, blockade of Acb AMPA receptors also blocks cocaine-conditioned locomotion (Hotsenpiller et al, 2001), and mGluR agonists injected into the Acb cause elevated locomotor activity in unconditioned animals (Swanson and Kalivas, 2000), suggesting an interdependence of dopaminergic and glutamatergic mechanisms in the mediation of conditioned locomotion. Nonetheless, the release of DA into the Acb from the terminations of axons projecting from the VTA is an essential component of the expression of conditioned locomotion and what is likely disrupted by bicuculline infusions into the RMTg that result in the suppression of conditioned locomotion.

Significance and concluding remarks. The present findings have implications for the clinic, insofar as depression is well known to be linked to neural mechanisms that regulate locomotor activity. Indeed, lethargy and lack of motivation are core symptoms of major depressive disorder (American Psychiatric Association, 2013). The LHb, which activates and inactivates the RMTg and VTA, respectively (Hong et al, 2011), is overactive in rat models of depression (Caldecott-Hazard et al, 1988; Shumake et al, 2003; Li et al, 2013) and depressed human patients (Morris et al, 1999; Roiser et al, 2009). Inhibition of the LHb reverses depression-like behaviors in rats (Winter et al, 2011) and the LHb has been targeted with some success in deep brain stimulation to treat treatment-resistant depression in humans (Sartorius et al, 2010; Schneider et al, 2013). Clearly, however, the RMTg, LHb, and VTA do not act alone to mediate complex behaviors and pathophysiologies but rather require interactions with numerous other brain structures, including, but not limited to, the raphe nuclei, pedunculopontine and laterodorsal tegmental nuclei, lateral hypothalamic-preoptic continuum, extended amygdala, ventral striatopallidum, septum-preoptic system, and orbitofrontal cortex (Kowski et al, 2008; Jhou et al, 2009b; Kaufling et al, 2009; Barrot and Thome, 2011; Lavezzi and Zahm, 2011; Lavezzi et al, 2011; Bourdy and Barrot, 2012). We show here functional data consistent with RMTg involvement in the modulation of locomotion. Future studies may more definitively establish an involvement of the RMTg in mood disorders and regulation of that involvement by some of the aforementioned structures.

\section{FUNDING AND DISCLOSURE}

The authors declare no conflict of interest.

\section{ACKNOWLEDGEMENTS}

The work was supported by USPHS NIH grants NS-23805 and T32 GM008306.

\section{REFERENCES}

American Psychiatric Association (2013). Diagnostic and Statistical Manual of Mental Disorders. 5th edn. American Psychiatric Publishing: Arlington, VA, USA.

Austin MC, Kalivas PW (1989). Blockade of enkephalinergic and GABAergic mediated locomotion in the nucleus accumbens by muscimol in the ventral pallidum. Jpn J Pharmacol 50: 487-490. 
Austin MC, Kalivas PW (1990). Enkephalinergic and GABAergic modulation of motor activity in the ventral pallidum. J Pharmacol Exp Ther 252: 1370-1377.

Austin MC, Kalivas PW (1991). Dopaminergic involvement in locomotion elicited from the ventral pallidum/substantia innominata. Brain Res 542: 123-131.

Balcita-Pedicino JJ, Omelchenko N, Bell R, Sesack SR (2011). The inhibitory influence of the lateral habenula on midbrain dopamine cells: ultrastructural evidence for indirect mediation via the rostromedial mesopontine tegmental nucleus. J Comp Neurol 519: 1143-1164.

Barrot M, Thome J (2011). Discovering a new anatomical structure in the brain: implications for neuropsychiatry and therapy. World J Biol Psychiatry 12(Suppl 1): 19-22.

Bayer VE, Towle AC, Pickel VM (1991). Ultrastructural localization of neurotensin-like immunoreactivity within dense core vesicles in perikarya, but not terminals, colocalizing tyrosine hydroxylase in the rat ventral tegmental area. J Comp Neurol 311: 179-196.

Beninger RJ, Hahn B (1983). Pimozide blocks establishment but not expression of amphetamine-produced environment-specific conditioning. Science 220: 1304-1306.

Beninger RJ, Herz RS (1986). Pimozide blocks establishment but not expression of cocaine-produced environment specific conditioning. Life Sci 38: 1425-1431.

Berridge KC (2012). From prediction error to incentive salience: mesolimbic computation of reward motivation. Eur J Neurosci 35: 1124-1143.

Berridge KC, Robinson TE (1998). What is the role of dopamine in reward: hedonic impact, reward learning, or incentive salience? Brain Res Rev 28: 309-369.

Blaha CD, Coury A, Fibige HC, Phillips AG (1990). Effects of neurotensin on dopamine release and metabolism in the rat striatum and nucleus accumbens: cross-validation using in vivo voltammetry and microdialysis. Neuroscience 34: 699-705.

Bourdy R, Barrot M (2012). A new control center for dopaminergic systems: pulling the VTA by the tail. Trends Neurosci 35: 681-690.

Bourdy R, Sanchez-Catalan MJ, Kaufling J, Balcita-Pedicino JJ, Freund-Mercier MJ, Veinante P et al (2014). Control of the nigrostriatal dopamine neuron activity and motor function by the tail of the ventral tegmental area. Neuropsychopharmacology (doi:10.1038/npp.2014.129; epub ahead of print).

Cador M, Taylor JR, Robbins TW (1991). Potentiation of the effects of reward-related stimuli by dopaminergic-dependent mechanisms in the nucleus accumbens. Psychopharmacology (Berl) 104: 377-385.

Caldecott-Hazard S, Mazziotta J, Phelps M (1988). Cerebral correlates of depressed behavior in rats, visualized using $14 \mathrm{C}$ 2-deoxyglucose autoradiography. J Neurosci 8: 1951-196.

Geisler S, Derst C, Veh RW, Zahm DS (2007). Glutamatergic afferents of the ventral tegmental area in the rat. J Neurosci 27: 5730-5743.

Geisler S, Zahm DS (2005). Afferents of the ventral tegmental area in the rat-anatomical substratum for integrative functions. $J$ Comp Neurol 490: 270-294.

Geisler S, Zahm DS (2006). Neurotensin afferents of the ventral tegmental area in the rat: [1] re-examination of their origins and [2] responses to acute psychostimulant and antipsychotic drug administration. Eur I Neurosci 24: 116-134.

Gold LH, Swerdlow NR, Koob GF (1988). The role of mesolimbic dopamine in conditioned locomotion produced by amphetamine. Behav Neurosci 102: 544-552.

Grimm JW, Hope BT, Wise RA, Shaham Y (2001). Neuroadaptation. Incubation of cocaine craving after withdrawal. Nature 412: 141-142.

Holstege G (1991). Descending motor pathways and the spinal motor system: limbic and non-limbic components. Prog Brain Res 87: 307-421.
Hong S, Jhou TC, Smith MK, Saleem KS, Hikosaka O (2011). Negative reward signals from the lateral habenula to dopamine neurons are mediated by rostromedial tegmental nucleus in primates. J Neurosci 31: 11457-11471.

Hotsenpiller G, Giorgetti M, Wolf ME (2001). Alterations in behaviour and glutamate transmission following presentation of stimuli previously associated with cocaine exposure. Eur $J$ Neurosci 14: 1843-1855.

Ikemoto S, Panksepp J (1999). The role of nucleus accumbens dopamine in motivated behavior: a unifying interpretation with special reference to reward-seeking. Brain Res Rev 31: 6-41.

Jhou T (2005). Neural mechanisms of freezing and passive aversive behaviors. J Comp Neurol 493: 111-114.

Jhou TC, Fields HL, Baxter MG, Saper CB, Holland PC (2009a). The rostromedial tegmental nucleus (RMTg), a GABAergic afferent to midbrain dopamine neurons, encodes aversive stimuli and inhibits motor responses. Neuron 61: 786-800.

Jhou TC, Gallagher M (2007). Paramedian raphe neurons that project to midbrain dopamine neurons are activated by aversive stimuli. Soc Neurosci Abstr 33: 425.5.

Jhou TC, Geisler S, Marinelli M, Degarmo BA, Zahm DS (2009b). The mesopontine rostromedial tegmental nucleus: a structure targeted by the lateral habenula that projects to the ventral tegmental area of Tsai and substantia nigra compacta. J Comp Neurol 513: 566-596.

Jhou TC, Good CH, Rowley CS, Xu S, Wang H, Burnham NW et al (2013). Cocaine drives aversive conditioning via delayed activation of dopamine-responsive habenular and midbrain pathways. J Neurosci 33: 7501-7512.

Johnson K, Churchill L, Klitenick MA, Hooks MS, Kalivas PW (1996). Involvement of the ventral tegmental area in locomotion elicited from the nucleus accumbens or ventral pallidum. J Pharmacol Exp Ther 277: 1122-1131.

Kalivas PW, Burgess SK, Nemeroff CB, Prange AJ Jr (1983). Behavioral and neurochemical effects of neurotensin microinjection into the ventral tegmental area of the rat. Neuroscience 8: 495-505.

Kalivas PW, Duffy P (1990). Effect of acute and daily cocaine treatment on extracellular dopamine in the nucleus accumbens. Synapse 5: 48-58.

Kalivas PW, Klitenick MA, Hagler H, Austin MC (1991). GABAergic and enkephalinergic regulation of locomotion in the ventral pallidum: involvement of the mesolimbic dopamine system. Adv Exp Med Biol 295: 315-326.

Kalivas PW, Stewart J (1991). Dopamine transmission in the initiation and expression of drug- and stress-induced sensitization of motor activity. Brain Res Rev 16: 223-244.

Kaufling J, Veinante P, Pawlowski SA, Freund-Mercier MJ, Barrot $M$ (2009). Afferents to the GABAergic tail of the ventral tegmental area in the rat. J Comp Neurol 513: 597-621.

Kaufling J, Waltisperger E, Bourdy R, Valera A, Veinante P, Freund-Mercier MJ et al (2010). Pharmacological recruitment of the GABAergic tail of the ventral tegmental area by acute drug exposure. Br J Pharmacol 161: 1677-1691.

Kelly PH, Moore KE (1976). Mesolimbic dopaminergic neurones in the rotational model of nigrostriatal function. Nature 263: 695-696.

Kelly PH, Seviour PW, Iversen SD (1975). Amphetamine and apomorphine responses in the rat following 6-OHDA lesions of the nucleus accumbens septi and corpus striatum. Brain Res 94: 507-522.

Kowski AB, Geisler S, Krauss M, Veh RW (2008). Differential projections from subfields in the lateral preoptic area to the lateral habenular complex of the rat. J Comp Neurol 507: 1465-1478.

Laitinen K, Crawley JN, Mefford IN, De Witte P (1990). Neurotensin and cholecystokinin microinjected into the ventral tegmental area modulate microdialysate concentrations of dopamine and metabolites in the posterior nucleus accumbens. Brain Res 523: 342-346. 
Lavezzi H, Parsley KP, Zahm DS (2011). Mesopontine rostromedial tegmental nucleus neurons projecting to the dorsal raphe and pedunculopontine tegmental nucleus: psychostimulant-elicted Fos expression and collateralization. Brain Struct Funct 217: 719-734.

Lavezzi H, Parsley KP, Zahm DS (2013). On the circuitry that mediates locomotor activation following injection of bicuculline into the lateral preoptic area. Soc Neurosci Abstr 674.06.

Lavezzi H, Zahm DS (2011). The mesopontine rostromedial tegmental nucleus: an integrative modulator of the reward system. Basal Ganglia 1: 191-200.

Lecca S, Melis M, Luchicchi A, Ennas MG, Castelli MP, Muntoni AL et al (2011). Effects of drugs of abuse on putative rostromedial tegmental neurons, inhibitory afferents to midbrain dopamine cells. Neuropsychopharmacol 36: 589-602.

Lecca S, Melis M, Luchicchi A, Muntoni AL, Pistis M (2012). Inhibitory inputs from rostromedial tegmental neurons regulate spontaneous activity of midbrain dopamine cells and their responses to drugs of abuse. Neuropsychopharmacol 37: 1164-1176.

Lenard LG, Beer B (1975). 6-Hydroxydopamine and avoidance: possible role of response suppression. Pharmacol Biochem Behav 3: 873-878.

Li K, Zhou T, Liao L, Yang Z, Wong C, Henn F et al (2013). $\beta C a M K I I$ in lateral habenula mediates core symptoms of depression. Science 341: 1016-1020.

Litwin LC, Goldstein JM (1994). Effects of neurotensin on midbrain dopamine neuronal activity. Drug Dev Res 32: 6-12.

Mary Christopher S, Butter CM (1968). Consummatory behaviors and locomotor exploration evoked from self-stimulation sites in rats. J Comp Physiol Psychol 66: 335-339.

Matsui A, Jarvie BC, Robinson BG, Hentges ST, Williams JT (2014). Separate GABA afferents to dopamine neurons mediate acute action of opioids, development of tolerance, and expression of withdrawal. Neuron 82: 1346-1356.

Matsui A, Williams JT (2011). Opioid-sensitive GABA inputs from rostromedial tegmental nucleus synapse onto midbrain dopamine neurons. J Neurosci 31: 17729-17735.

Mogenson GJ, Nielsen MA (1983). Evidence that an accumbens to subpallidal GABAergic projection contributes to locomotor activity. Brain Res Bull 11: 309-314.

Mogenson GJ, Swanson LW, Wu M (1985). Evidence that projections from substantia innominata to zona incerta and mesencephalic locomotor region contribute to locomotor activity. Brain Res 334: 65-76.

Mogenson GJ, Wu M, Manchanda SK (1979). Locomotor activity initiated by microinfusions of picrotoxin into the ventral tegmental area. Brain Res 161: 311-319.

Morris JS, Smith KA, Cowen PJ, Friston KJ, Dolan RJ (1999). Covariation of activity in habenula and dorsal raphé nuclei following tryptophan depletion. Neuroimage 10: 163-172.

Perrotti LI, Bolaños CA, Choi KH, Russo SJ, Edwards S, Ulery PG et al (2005). DeltaFosB accumulates in a GABAergic cell population in the posterior tail of the ventral tegmental area after psychostimulant treatment. Eur J Neurosci 21: 2817-2824.

Phillipson OT (1979). Afferent projections to the ventral tegmental area of Tsai and interfascicular nucleus: a horseradish peroxidase study in the rat. J Comp Neurol 187: 117-143.

Post RM, Lockfeld A, Squillace KM, Contel NR (1981). Drug environment interaction: context dependency of cocaine induced behavioral sensitization. Life Sci 28: 755-760.

Quirion R, Chiueh CC, Everist HD, Pert A (1985). Comparative localization of neurotensin receptors on nigrostriatal and mesolimbic dopaminergic terminals. Brain Res 327: 385-389.

Reynolds SM, Geisler S, Berod A, Zahm DS (2006). Neurotensin antagonist acutely and robustly attenuates locomotion that accompanies stimulation of a neurotensin-containing pathway from rostrobasal forebrain to the ventral tegmental area. Eur $J$ Neurosci 24: 188-196.
Roberts WW, Carey RJ (1965). Rewarding effect of performance of gnawing aroused by hypothalamic stimulation in the rat. J Comp Physiol Psychol 59: 317-324.

Robinson TE, Berridge KC (1993). The neural basis of drug craving: an incentive-sensitization theory of addiction. Brain Res Rev 18: 247-291.

Roiser JP, Levy J, Fromm SJ, Nugent AC, Talagala SL, Hasler G et al (2009). The effects of tryptophan depletion on neural responses to emotional words in remitted depression. Biol Psychiatry 66: 441-450.

Salamone JD, Correa M (2012). The mysterious motivational functions of mesolimbic dopamine. Neuron 76: 470-485.

Salamone JD, Correa M, Mingote S, Weber SM (2003). Nucleus accumbens dopamine and the regulation of effort in foodseeking behavior: implications for studies of natural motivation, psychiatry, and drug abuse. J Pharmacol Exp Ther 305: 1-8.

Sartorius A, Kiening KL, Kirsch P, von Gall CC, Haberkorn U, Unterberg AW et al (2010). Remission of major depression under deep brain stimulation of the lateral habenula in a therapy-refractory patient. Biol Psychiatry 67: e9-e11.

Schneider TM, Beynon C, Sartorius A, Unterberg AW, Kiening KL (2013). Deep brain stimulation of the lateral habenula complex in treatment-resistant depression: traps and pitfalls of trajectory choice. Neurosurgery 72: 184-193.

Seutin V, Massotte L, Dresse A (1989). Electrophysiological effects of neurotensin on dopaminergic neurones of the ventral tegmental area of the rat in vitro. Neuropharmacology 28: 949-954.

Shi WX, Bunney BS (1991). Neurotensin modulates autoreceptor mediated dopamine effects on midbrain dopamine cell activity. Brain Res 543: 315-321.

Shreve PE, Uretsky NJ (1988). Effect of GABAergic transmission in the subpallidal region on the hypermotility response to the administration of excitatory amino acids and picrotoxin into the nucleus accumbens. Neuropharmacology 27: 1271-1277.

Shreve PE, Uretsky NJ (1989). AMPA, kainic acid, and N-methylD- aspartic acid stimulate locomotor activity after injection into the substantia innominata/lateral preoptic area. Pharmacol Biochem Behav 34: 101-106.

Shreve PE, Uretsky NJ (1991). GABA and glutamate interact in the substantia innominata/lateral preoptic area to modulate locomotor activity. Pharmacol Biochem Behav 38: 385-388.

Shumake J, Edwards E, Gonzalez-Lima F (2003). Opposite metabolic changes in the habenula and ventral tegmental area of a genetic model of helpless behavior. Brain Res 963: 274-281.

Sotty F, Brun P, Leonetti M, Steinberg R, Soubrie P, Renaud B et al (2000). Comparative effects of neurotensin, neurotensin(8-13) and $[D-\operatorname{Tyr}(11)]$ neurotensin applied into the ventral tegmental area on extracellular dopamine in the rat prefrontal cortex and nucleus accumbens. Neuroscience 98: 485-492.

Steinberg R, Brun P, Fournier M, Souilhac J, Rodier D, Mons G et al (1994). SR 48692, a non- peptide neurotensin receptor antagonist differentially affects neurotensin-induced behaviour and changes in dopaminergic transmission. Neuroscience 59: 921-929.

Swanson CJ, Kalivas PW (2000). Regulation of locomotor activity by metabotropic glutamate receptors in the nucleus accumbens and ventral tegmental area. J Pharmacol Exp Ther 292: 406-414.

Tarsy D, Pycock C, Meldrum B, David C (1975). Rotational behavior induced in rats by intranigral picrotoxin. Brain Res 89 : 160-165.

Taylor JR, Robbins TW (1984). Enhanced behavioural control by conditioned reinforcers following microinjections of D-amphetamine into the nucleus accumbens. Psychopharmacology (Berl) 84: 405-412.

Taylor JR, Robbins TW (1986). 6-Hydroxydopamine lesions of the nucleus accumbens, but not of the caudate nucleus, attenuate enhanced responding with reward-related stimuli produced by intra-accumbens D-amphetamine. Psychopharmacology (Berl) 90: 390-397. 
Wasserman DI, Wang HG, Rashid AJ, Josselyn SA, Yeomans JS (2013). Cholinergic control of morphine-induced locomotion in rostromedial tegmental nucleus versus ventral tegmental area sites. Eur J Neurosci 38: 2774-2785.

Werkman TR, Kruse CG, Nievelstein H, Long SK, Wadman WJ (2000). Neurotensin attenuates the quinpirole-induced inhibition of the firing rate of dopamine neurons in the rat substantia nigra pars compacta and the ventral tegmental area. Neuroscience 95: 417-423.

Willins DL, Wallace LJ, Miller DD, Uretsky NJ (1992). Alpha-amino- 3-hydroxy-5-methylisoxazole-4-propionate/kainate receptor antagonists in the nucleus accumbens and ventral pallidum decrease the hypermotility response to psychostimulant drugs. J Pharmacol Exp Ther 260: 1145-1151.

Winter C, Vollmayr B, Djodari-Irani A, Klein J, Sartorius A (2011). Pharmacological inhibition of the lateral habenula improves depressive-like behavior in an animal model of treatment resistant depression. Behav Brain Res 216: 463-465.

Woulfe J, Beaudet A (1989). Immunocytochemical evidence for direct connections between neurotensin-containing axons and dopaminergic neurons in the rat ventral midbrain tegmentum. Brain Res 479: 402-406.

Yetnikoff L, Lavezzi HN, Reichard RA, Zahm DS (2014). An update on the connections of the ventral mesencephalic dopaminergic complex. Neuroscience 282C: 23-48.

Zahm DS, Arends JJA, Parsley KP, Geisler S (2011). Projection to the mesopontine rostromedial tegmental nucleus from the lateral preoptic area. Soc Neurosci Abstr 79.09.

Zahm DS, Grosu S, Williams EA, Qin S, Berod A (2001). Neurons of origin of the neurotensinergic plexus enmeshing the ventral tegmental area in rat: retrograde labeling and in situ hybridization combined. Neuroscience 104: 841-851.

Zahm DS, Parsley KP, Schwartz ZM, Cheng AY (2013). On lateral septum-like characteristics of outputs from the accumbal hedonic 'hotspot' of Pecina and Berridge with commentary on the transitional nature of basal forebrain 'boundaries'. J Comp Neurol 521: 50-68.

Zahm DS, Schwartz ZM, Lavezzi HN, Yetnikoff L, Parsley KP (2014). Comparison of the locomotor-activating effects of bicuculline infusions into the preoptic area and ventral pallidum. Brain Struct Funct 219: 511-526. 